\title{
DESACUERDO ENTRE PARES EPISTÉMICOS EN EL DEBATE NATURALEZA-CULTURA
}

Epistemic Peer Disagreement in the Nature-Nurture Debate

\author{
NAHUEL PALLITTO \\ Instituto de Filosofía "Dr. Alejandro Korn", CONICET, ARGENTINA \\ nahuelpallitto@gmail.com
}

\begin{abstract}
Scientific disagreements constitute valuable resources for reflecting on epistemic peer disagreements. In this essay I engage in the debate whether epistemic peers who disagree should be conciliatory or steadfast by examining how scientists actually react in the so called nature-nurture debate. The main conclusion of the analysis is that, when taking into consideration concrete epistemic practices with peers responding to different epistemic perspectives, scientists have good reasons to be steadfast. At the same time, the theoretical conceptualizations of the epistemology of peer disagreement illuminates certain aspects of the nature-nurture debate, such as its long persistence. Therefore, this article contributes both to the debate over the epistemology of disagreement and to the understanding of a never-ending controversy in the life sciences.
\end{abstract}

Keywords: Epistemology $\bullet$ epistemic peer disagreements $\bullet$ scientific controversies $\bullet$ naturenurture debate.

\section{Introducción}

Un escrutinio rápido al pasado y presente de las Ciencias Naturales muestra que los desacuerdos entre pares científicos han sido y continúan siendo abundantes (Hulme 2009; Machamer et al. 2000). Con frecuencia, los científicos pueden presentar desacuerdos respecto a los aspectos del mundo relevantes a explicar, a la pertinencia de las preguntas a formular, a los métodos a emplear, a las hipótesis y teorías a aceptar, a qué constituye evidencia y cómo la misma debe ser evaluada e, incluso, respecto 
a sus creencias o actitudes doxásticas. En algunos casos, estos desacuerdos son caracterizados apelando a factores no epistémicos o extracientíficos, tal como cuando se recurre a la presencia de sesgos cognitivos ocasionados por presiones institucionales, deseo de fama, orgullo o valores ético-políticos. En otros casos, las discrepancias se explican recurriendo a factores epistémicos, circunscribiendo los desacuerdos a la cantidad y tipo de evidencia disponible y a las evaluaciones que realizan los investigadores a partir de la misma. Los desacuerdos del primero tipo suelen ser considerados irracionales, mientras que aquellos del segundo tipo suelen ser considerados racionales (Junges 2013).

En las últimas décadas, el fenómeno del desacuerdo ha sido intensamente explorado por el campo disciplinar de la Epistemología Social. En particular, muchas de las reflexiones se han focalizado en el desacuerdo entre pares epistémicos en lo que refiere a sus actitudes doxásticas, o creencias (Douven 2010; Kelly 2005; 2010; Lo Guercio 2012; 2015; 2016). En principio, se puede sostener que dos sujetos desacuerdan doxásticamente cuando presentan creencias diferentes e incompatibles, esto es, cuando por ejemplo uno cree en una determinada proposición y el otro cree en su negación. A su vez, dichos sujetos se consideran pares epistémicos si poseen (aproximadamente) la misma evidencia y si son (aproximadamente) iguales en lo que respecta a sus virtudes epistémicas - esto es, inteligencia, perspicacia, honestidad, meticulosidad, entre otras - . En situaciones como las mencionadas, emerge una situación epistémica problemática. Es decir, si existe un desacuerdo pero la evidencia es la misma y ninguno aventaja epistémicamente al otro al momento de evaluar dicha evidencia, ¿es razonable el desacuerdo? ¿no será que alguno de los dos evaluó la evidencia de manera inadecuada? Y a su vez, ¿pueden los sujetos que desacuerdan continuar manteniendo sus actitudes doxásticas iniciales o eso los volvería irracionales? ¿cómo debería un sujeto ajustar sus actitudes doxásticas en virtud del desacuerdo con un par epistémico? Las llamadas posturas conciliadoras consideran que mantener las creencias originales es irracional y que, por el contrario, lo razonable es suspender el juicio o adoptar la visión del otro (Christensen 2007; Elga 2007; Feldman 2006). Por el contrario, las denominadas posturas obstinadas consideran que, al menos en ciertos casos, es razonable mantener las creencias iniciales (Kelly 2010; Lo Guercio 2012; 2015; 2016; Wedgwood 2010). Dicho en otros términos, para las posiciones conciliadoras no puede darse el caso de que pares epistémicos desacuerden de forma racional, mientras que para las posiciones obstinadas es, en ocasiones, perfectamente posible que lo dicho acontezca. Lo que en todo caso pareciera quedar claro es que no existe acuerdo entre los epistemólogos sociales respecto a cómo pares epistémicos deberían reaccionar frente a la percepción del desacuerdo. Al mismo tiempo, cabe reconocer en la bibliografía específica un déficit de estudios de casos empíricos concretos. En la mayoría de los trabajos, los argumentos se articulan alrededor de situaciones hipotéticas generadas con el solo fin de señalar los puntos fuertes de las 
reflexiones de los autores que los proponen. Sin quitar legitimidad a dicha estrategia, la cual sin dudas es fundamental en Filosofía, considero que la incorporación de una base empírica de desacuerdos reales, con sujetos epistémicos concretos, puede enriquecer enormemente las reflexiones sobre los desacuerdos entre pares epistémicos.

En virtud de lo dicho, el objetivo del presente trabajo consiste en articular una defensa de las posturas obstinadas a partir del análisis de un desacuerdo real en las ciencias de la vida. Dicha defensa se articulará mediante el análisis de una de las controversias más resonantes y persistentes de la Biología del Comportamiento, aquella que se conoce como debate naturaleza-cultura (Fox Keller 2010; Tabery 2009). Sin entrar aquí en mayores detalles, los cuales serán provistos en el apartado correspondiente, una de las formas que adopta el debate se puede caracterizar de manera aproximada como presentando científicos que consideran que el comportamiento humano depende de factores biológicos y otros que consideran que éstos no presentan ningún rol preponderante. Así, puede definirse un escenario en el cual al menos dos o más científicos presentan actitudes doxásticas diferentes e incompatibles, creencias respecto a los determinantes del comportamiento humano, y en el cual los involucrados exhiben una clara percepción del desacuerdo. Conforme a las posturas conciliadoras, los científicos que desacuerdan estarían siendo irracionales al sostener las actitudes doxásticas que dan continuidad al debate, siempre y cuando se considere que los científicos son pares epistémicos. En efecto, diversos autores consideran que la controversia persiste porque cada una de las partes privilegia uno de los dos polos por razones no epistémicas (Jumonville 2002; Paul 1998). Sin embargo, procuraré argumentar que existen buenos motivos para mantenerse obstinados y que eso no atenta contra la racionalidad del desacuerdo. Como se aprecia del objetivo fundamental, la intención es aplicar los esquemas conceptuales provistos por la bibliografía a un sistema empírico concreto y repensar las respuestas a la pregunta por el desacuerdo entre pares epistémicos en función del ejemplo provisto. Asimismo, la bibliografía sobre desacuerdos entre pares epistémicos permite iluminar ciertos aspectos del debate en cuestión, haciendo del presente ensayo una contribución doble.

Con el fin propuesto, en primer lugar presentaré los aspectos principales de las teorías sobre los desacuerdos entre pares epistémicos. En segundo lugar, describiré el debate naturaleza-cultura, identificando algunas de las partes involucradas así como caracterizando el modo en que puede ser entendido el desacuerdo. En tercer lugar, analizaré el debate a la luz de los esquemas conceptuales provistos por la teoría sobre los desacuerdos entre pares epistémicos, brindando una explicación plausible y razonable de por qué las partes mantienen posturas obstinadas en lugar de conciliar. Por último, presentaré algunas consecuencias y conclusiones del caso aquí analizado, tanto para la Epistemología Social como para el debate naturaleza-cultura. 


\section{Desacuerdo entre pares epistémicos}

\subsection{Caracterización general del fenómeno del desacuerdo}

Para comprender el debate naturaleza-cultura desde la perspectiva de los desacuerdos entre pares epistémicos, antes debemos caracterizar en qué consiste un desacuerdo y qué significa que dos personas sean pares epistémicos. Comencemos por lo primero. En la bibliografía especializada se reconocen al menos dos planos en los que dos sujetos pueden desacordar. Uno corresponde al plano de las creencias o actitudes doxásticas y el otro corresponde al dominio de las acciones (Frances 2013; Lo Guercio 2015). Así, por ejemplo, dos personas pueden desacordar respecto al valor de verdad de la proposición "el consumo de tabaco es un factor de riesgo para el cáncer de pulmón" y, sin embargo, decidir ambos no fumar. O, viceversa, pueden acordar respecto al valor de verdad de la proposición y, no obstante, diferir en cuanto al comportamiento adoptado, siendo que uno es fumador y el otro no. Aquí me ocuparé de los desacuerdos del primer tipo, aquellos que involucran diferencias de creencias. Se dice que dos sujetos, $S_{1}$ y $S_{2}$ desacuerdan doxásticamente cuando discrepan respecto al valor de verdad de cierta proposición $P$. Es decir, cuando, por ejemplo, $S_{1}$ cree $P$ y $S_{2}$ cree $\neg P$. $\mathrm{O}$, de manera equivalente, cuando $S_{1}$ cree $\neg P$ y $S_{2}$ cree $P$. A su vez, los desacuerdos pueden ser fácticos o normativos, también llamados evaluativos. Los desacuerdos fácticos surgen cuando la proposición $P$ refiere a cómo es o cómo se comporta el mundo. En ese sentido, la proposición acerca de la relación entre el consumo de tabaco y el cáncer de pulmón es de tipo fáctica. En cambio, los desacuerdos normativos o evaluativos surgen cuando la proposición $P$ refiere a cuestiones de gusto, de humor, estéticas o morales. Un ejemplo de una proposición de este tipo es: "sobornar a un juez es incorrecto". 1

Si bien en las ciencias naturales son comunes ambos tipos de desacuerdos, nos centraremos en esta oportunidad en los desacuerdos fácticos, es decir, en aquellos que presentan diferencias entre dos sujetos respecto al valor de verdad de alguna proposición $P$ acerca del mundo. ${ }^{2}$ Uno de los elementos epistemológicos que sobresale en este tipo de desacuerdos es la evidencia $(E)$. Al ser $P$ una proposición fáctica, requiere de un cuerpo de evidencia que le dé sustento y que justifique que un sujeto epistémico determinado la crea. Comúnmente, se sostiene que la relación de apoyo evidencial es diádica, lo cual significa que un determinado cuerpo de evidencia $E$ apoya una proposición $P$ de manera unívoca e inequívoca. Es decir, o $E$ apoya $P$ o $E$ apoya $\neg P$, negando la posibilidad de que $E$ apoye simultáneamente la afirmación y su negación. A la tesis que considera que hay una única respuesta racional posible para cualquier cuerpo de evidencia se la conoce con el nombre unicidad (White 2005). El segundo elemento central corresponde precisamente al sujeto epistémico que evalúa esa evidencia. Aquí lo que suele resaltarse son las aptitudes epistémicas del evaluador, tales 
como la inteligencia, perspicacia, honestidad, atención, meticulosidad e imparcialidad, entre otras. Las aptitudes epistémicas adecuadas garantizarían la racionalidad de una actitud doxástica formada a partir de la relación de apoyo evidencial de $E$ hacia $P$. Podemos, entonces, valernos de la siguiente definición de desacuerdo dada por Lo Guercio (2015, p.26):

Dos sujetos $S_{1}$ y $S_{2}$ están en desacuerdo acerca del contenido proposicional $P$ cuando la corrección de la actitud doxástica de $S_{1}$ hacia $P$ en relación con las circunstancias de evaluación de $S_{1}$ previene la corrección de la actitud doxástica de $S_{2}$ hacia $P$ en relación con las circunstancias de evaluación de $S_{2}$.

Las circunstancias de evaluación fijan un mundo posible y un tiempo determinado. El desacuerdo resulta tal en la medida en que lo que cree $S_{1}$ respecto a $P$, a partir del apoyo evidencial $E$, es relevante en las circunstancias de evaluación de $S_{2}$. Por ejemplo, si el tiempo de evaluación de una determinada proposición varía, puede darse el caso de que actitudes doxásticas contrapuestas se encuentren ambas justificadas. Tomando un ejemplo de Lo Guercio (2015), si una persona cree que la proposición "Sócrates está sentado" es verdadera a las 2 a.m y otra persona cree que la proposición "Sócrates está sentado" es falsa a las 3 a.m., no hay un desacuerdo en un sentido interesante, dado que $S_{1}$ y $S_{2}$ difieren en las circunstancias de evaluación.

Ahora bien, hasta el momento hemos caracterizado en qué consiste un desacuerdo fáctico y cuáles son los elementos epistemológicos relevantes a tener en cuenta para su descripción. Hemos visto que se requiere de al menos dos sujetos $S_{1}$ y $S_{2}$ que generen actitudes doxásticas diferentes e incompatibles a partir de un determinado apoyo evidencial de $E$ hacia $P$. Debemos a continuación profundizar en las relaciones posibles entre $S_{1}$ y $S_{2}$, entre $E$ y los sujetos epistémicos $S_{1}$ y $S_{2}$, y en la naturaleza de E. Esto resulta necesario en la medida en que lo que nos interesa es caracterizar un desacuerdo real en las ciencias de la vida entre lo que podrían ser considerados pares epistémicos.

\subsection{Paridad epistémica}

La noción de paridad epistémica captura, por un lado, una de las posibles relaciones entre dos sujetos epistémicos $S_{1}$ y $S_{2}$ y, por el otro, las relaciones que éstos mantienen con la evidencia E. Respecto al primer punto, se espera que $S_{1}$ y $S_{2}$ cumplan con lo que se conoce como (i) condición de igualdad cognitiva (Lackey 2010). Según esta condición, $S_{1}$ y $S_{2}$ son cognitivamente iguales con respecto a la cuestión P cuando son igualmente competentes, inteligentes e imparciales en su evaluación de la evidencia y los argumentos relevantes para la cuestión $P$. Asimismo, se espera que se cumpla con la (ii) condición de igualdad evidencial (Lackey 2010). De acuerdo con 
esta segunda condición, $S_{1}$ y $S_{2}$ son evidencialmente iguales con respecto a la cuestión $P$ cuando tienen igual familiaridad con la evidencia y los argumentos relevantes para la cuestión $P$. Si dos individuos satisfacen las condiciones (i) y (ii), entonces son pares epistémicos. $\mathrm{O}$, dicho de otra manera, dos individuos son pares epistémicos con respecto a $P$ si y sólo si satisfacen las condiciones de paridad evidencial y paridad cognitiva.

Ser o no ser pares epistémicos respecto a cierta cuestión no es una atribución absoluta, sino que, como reconoce Lo Guercio (2015, p.32), la atribución es sensible al contexto, en el sentido que:

[... ] qué cuenta como tener la misma evidencia o las mismas virtudes cognitivas depende del estándar de precisión relevante en el contexto. Si el estándar del contexto es extremadamente exigente, cualquier diferencia en evidencia o virtudes cognitivas, por mínima que sea, impedirá considerar a dos sujetos pares epistémicos. En cambio, si los estándares en rigor son más permisivos alcanzará con que los sujetos posean aproximadamente la misma evidencia y aproximadamente las mismas virtudes cognitivas para que podamos considerarlos pares epistémicos (énfasis del autor).

En virtud de lo dicho en este apartado, cabe entonces reconocer dos preguntas diferentes pero relacionadas: la pregunta por el desacuerdo y la pregunta por la posición epistémica de los sujetos que desacuerdan. Combinadas, la pregunta que suele prevalecer en la bibliografía específica es: ¿cómo debería un sujeto $S_{1}$ ajustar sus actitudes doxásticas hacia una proposición $P$ en virtud del desacuerdo reconocido con un par epistémico reconocido $S_{2}$ ? Esta pregunta es relevante dado que si $S_{1}$ cree que $P$ y, a su vez, considera que $S_{2}$ es un par epistémico del cual tiene evidencia justificada que cree $\neg P, S_{1}$ posee evidencia de segundo orden de que puede haber cometido un error de apreciación de $E$. A continuación, presentaré dos grupos de respuestas posibles a dicho interrogante.

\subsection{Dos posturas frente a los desacuerdos entre pares epistémicos}

Que cierto sujeto $S_{1}$ reconozca que otro sujeto $S_{2}$ desacuerda con él conlleva que $S_{1}$ adquiera la creencia justificada de que $S_{2}$ adoptó una actitud doxástica diferente a la suya. Al mismo tiempo, si $S_{1}$ posee razones independientes al caso en cuestión para considerar que $S_{2}$ es un par epistémico, se genera una situación epistémica problemática. ¿Debería $S_{1}$ modificar su creencia en virtud del conocimiento del desacuerdo con un par epistémico $S_{2} ?^{3}$ De acuerdo con ciertos autores, frente al descubrimiento del desacuerdo con un par epistémico respecto de una proposición $P, S_{1}$ debe revisar su actitud doxástica inicial (Christensen 2007; Elga 2007; Feldman 2006). A las posturas que reclaman revisar las actitudes doxásticas iniciales se las conoce como conciliadoras. Se puede conciliar suspendiendo el juicio respecto de $P$ o adoptando 
la creencia del par epistémico (Frances 2013). Un segundo grupo de autores considera que es racionalmente permisible, al menos en ciertas circunstancias, mantener la creencia inicial hacia $P$ (Kelly 2010; Lo Guercio 2012; 2015; 2016; Wedgwood 2010). A estas posturas se las conoce como obstinadas.

Clave en la lectura de los dos grupos de posturas presentados es el modo en que se configura la relación de apoyo evidencial. Como ya fue adelantado, se suele argumentar, particularmente del lado de las posturas conciliadoras, que la relación de apoyo evidencial es diádica y que siempre es posible determinar sin error si dos individuos poseen la misma evidencia y determinar de manera no controvertida el grado de apoyo que un cuerpo de evidencia proporciona a cierta proposición. A estas dos tesis se las denomina tesis de neutralidad evidencial y tesis de neutralidad cogniti$v a$, respectivamente (Lo Guercio 2016). La conjunción de las tesis implica que "todo desacuerdo entre pares epistémicos involucra un error de desempeño cognitivo" (Lo Guercio 2016, p.327). De satisfacerse estas condiciones, no cabría la posibilidad de desacordar racionalmente, dado que en todo caso la evidencia funcionaría como árbitro neutral entre actitudes doxásticas en disputa. Sin embargo, son varios los autores que se han pronunciado en contra de esta relación diádica y, por el contrario, han sostenido la necesidad de incorporar un tercer elemento en la relación de apoyo evidencial. Por ejemplo, tanto Igor Douven (2009) como Nicolás Lo Guercio (2012; 2015) proponen que la relación de apoyo evidencial es triádica. El primer autor sostiene que la relación se da entre creencias, evidencias y ciertos factores subjetivos, mientras que el segundo asevera que un cuerpo de evidencia $\mathrm{E}$ apoya una proposición $P$ tan solo en relación con a una perspectiva epistémica $R$. De acuerdo a este tercer elemento que propone Lo Guercio (2012; 2015; 2016), la relación de apoyo evidencial depende de ciertos compromisos acerca de (1) la naturaleza de la evidencia, de (2) ciertas reglas o criterios para evaluar dicha evidencia y de (3) las metas epistémicas involucradas y el orden de preferencias establecidas entre ellas. Por ejemplo, dos sujetos epistémicos pueden diferir en cuanto a lo que consideran admisible como evidencia (1), pueden diferir acerca de qué peso debe otorgarse a diferentes tipos de evidencia (2) o pueden evaluar la evidencia en el marco de distintos objetivos epistémicos, como ser adecuación empírica, éxito predictivo, simplicidad, coherencia, entre otros (3). Así, el grado en que un cuerpo de evidencia vuelve racional la adopción de una actitud doxástica hacia una proposición sería relativo a una perspectiva epistémica $R$. Nótese que el peso está puesto en la racionalidad de la actitud doxástica generada, no en su valor efectivo de verdad.

\subsection{Desacuerdo fuerte y desacuerdo débil}

La inclusión de la noción de perspectiva epistémica permite rechazar la idea de que todo desacuerdo se genera por un error de apreciación de la evidencia y permite 
salvar la racionalidad de los desacuerdos entre pares epistémicos. De acuerdo a la definición de pares epistémicos provista anteriormente, ésta solo exige que los sujetos en disputa posean (aproximadamente) las mismas virtudes cognitivas y posean (aproximadamente) la misma evidencia y familiaridad con las razones esgrimidas. No obstante, frente al reconocimiento que la relación de apoyo evidencial es triádica, Lo Guercio (2015, pp.76-7) propone distinguir entre dos tipos de paridades epistémicas diferentes:

Paridad Epistémica Fuerte: Dos sujetos son pares epistémicos fuertes respecto de una proposición $P$ si y solo si (1) poseen (aproximadamente) las mismas virtudes epistémicas, (2) poseen (aproximadamente) la misma información relevante para $P$ y (3) sus perspectivas epistémicas son semejantes.

Paridad Epistémica Débil: Dos sujetos son pares epistémicos débiles respecto de una proposición $P$ si y solo si (1) poseen (aproximadamente) las mismas virtudes epistémicas, (2) poseen (aproximadamente) la misma información relevante para $P$ y (3) sus perspectivas epistémicas son diferentes (énfasis propio).

A su vez, en virtud de esta distinción, sugiere clasificar los desacuerdos en dos tipos (Lo Guercio 2015, p.78):

Desacuerdo Débil: Desacuerdos entre pares epistémicos fuertes.

Desacuerdo Fuerte: Desacuerdos entre pares epistémicos débiles.

Estas disquisiciones resultan sumamente relevantes en el contexto del presente ensayo. Si la racionalidad de una actitud doxástica determinada depende de una perspectiva epistémica particular, entonces se pueden adoptar diferentes actitudes doxásticas racionales hacia una misma proposición, negando con ello la existencia de una única postura objetivamente correcta al respecto. Es decir, en los casos de desacuerdo fuerte, una controversia puede perpetuarse en el tiempo sin necesidad de acusar a alguno de los sujetos epistémicos involucrados de estar generando creencias de forma irracional. A su vez, dado que desde las perspectivas epistémicas en juego actitudes doxásticas incompatibles pueden ser todas ellas racionales, no hay motivos para conciliar, es decir, suspender el juicio respecto a una creencia o adoptar la creencia del par epistémico.

En el próximo apartado ofreceré una caracterización del debate naturaleza-cultura. Luego, argumentaré que dicha controversia puede ser entendida, sin descartar la presencia de factores no epistémicos, como un caso de desacuerdo fuerte entre pares epistémicos débiles. Realizado este movimiento, mostraré que el caso aquí analizado apoya las posturas que consideran que, al menos en ciertos situaciones, es racional ser obstinado y mantener las creencias iniciales. 


\section{El debate naturaleza-cultura}

Pocas controversias científicas poseen la duración y el alcance que presenta el debate naturaleza-cultura. Como reconoce Evelyn Fox Keller (2010), una de las características más sorprendentes del debate es el resultado contradictorio de que siempre que parece haber sido resuelto, nos topamos con una negativa del debate a perecer. Resulta difícil hallar una única caracterización posible de la controversia, siendo que diferentes preguntas suelen caer bajo la misma denominación. La nota común es la supuesta oposición entre dos dominios. Así, algunas veces se presenta como la oposición entre lo innato y lo adquirido, otras como la oposición entre lo genético y lo ambiental y en ciertas ocasiones como la oposición entre lo hereditario y lo aprendido. ${ }^{4} \mathrm{Al}$ margen de los diferentes significados de los conceptos de la disyunción, se considera que hay algo sustantivo e interno al individuo que prexiste a las dinámicas culturales a las que éste se expone después de su nacimiento. Desde luego, las alternativas mencionadas consisten en sí mismas en una fuente de variación y de potenciales desacuerdos. Concebir el debate naturaleza-cultura como la oposición entre lo genético y lo ambiental es diferente a concebirlo como la oposición entre lo innato y lo adquirido. En ese sentido, dos sujetos que respondan de manera diferente a la controversia pensando el debate desde esos diferentes ángulos, no desacuerdan en un sentido interesante, al menos no de forma evidente.

Un segundo germen de confusión reside en aplicar la disyunción en al menos dos fenómenos diferentes. Muchas veces, los investigadores se preguntan por las influencias de ciertos factores en el desarrollo de un individuo. Estos factores pueden ser clasificados como biológicos (genes, neurotransmisores, hormonas, entre otros) o culturales (influencias familiares, relaciones entre pares, estatus socioeconómico). La pregunta subyacente es el grado y tipo de influencia que presentan dichos factores en el desarrollo de ciertos rasgos en un mismo individuo, o dicho de otra manera, el grado de plasticidad fenotípica que presentan ciertos rasgos. ${ }^{5}$ Sin embargo, en otras oportunidades, la pregunta no refiere al desarrollo individual sino a las diferencias entre individuos en poblaciones determinadas. Por ejemplo, ante la variación en un rasgo fenotípico particular, como puede ser la agresión, los investigadores se preguntan cuánto de la variación fenotípica puede ser atribuida a variación genética y cuánto de esa misma variación puede ser atribuida a variación ambiental (DiLalla 2003). Como puede observarse, la disyunción entre naturaleza y cultura se aplica a explicar diferencias entre individuos en un rasgo y no a explicar cómo afectan ciertos factores al desarrollo del mismo en un único individuo. Hay un cambio de explanandum.

Para evitar este tipo de confusiones, me centraré tan solo en una de las maneras posibles de comprender el debate. La elección no se vincula con la importancia asignada a dicho modo de interpretarlo, sino que simplemente procura evitar equívocos 
que puedan ser atribuidos a las diferentes formas que adopta la controversia. Entenderé, entonces, al debate naturaleza-cultura en su versión ontogenética y circunscribiendo la disyunción a los factores internos al individuo (comúnmente englobados bajo el rótulo "naturaleza") y los factores externos al mismo (englobado bajo la denominación "cultura"). Entre los primeros, se pueden reconocer una multiplicidad de factores, tales como genes, neurotransmisores, circuitos neuronales, estructuras cerebrales, hormonas, entre muchos otros. Los segundos, involucran estatus socioeconómico, prácticas disciplinares, relaciones parentales y entre pares, niveles de educación, estilos de comunicación, entre otros. Asimismo, cabe resaltar que las partes en disputa suelen contener investigadores de formaciones diversas. Dentro de la Biología del Comportamiento Humano, por ejemplo, se pueden mencionar distintos programas de investigación, tales como la Genética del Comportamiento, la Neurobiología, la Ecología del Comportamiento y la Teoría de los Sistemas del Desarrollo (TSD), por solo nombrar algunos de ellos (Longino 2013 ofrece una caracterización completa y rigurosa de estos programas). En general, las diferentes respuestas al debate dependen, en alguna medida, de esta estructuración disciplinar. Tal es así, que en lo que sigue del apartado exhibiré el debate, de acuerdo a la interpretación propuesta anteriormente, tomando en consideración las diferencias entre dos de los diversos programas de investigación que constituyen a la Biología del Comportamiento Humano: la Genética del Comportamiento y la TSD.

Hechas las aclaraciones pertinentes, resta especificar sobre qué proposición fáctica efectivamente desacuerdan los científicos. Sin embargo, reconocer una proposición puntual sobre la que los investigadores involucrados en el debate desacuerdan es sumamente complicado, ya que éstas dependen de los sistemas bajo estudio. Por dicho motivo, especificaré una familia de proposiciones que comparten entre sí un parecido de familia. La proposición modelo $P_{m}$ puede ser expresada en los siguientes términos: "El factor interno $X$ del sujeto $Y$ predispone el comportamiento $Z$ en $Y$ ". A partir de esta formulación, distintas proposiciones pueden ser elaboradas, tal como "variaciones de la región promotora del gen transportador de serotonina predispone a Juan a ser agresivo". Los desacuerdos, entonces, se dan sobre las especificaciones de $P_{m}$ y no directamente sobre la proposición que únicamente sirve de ejemplar. Nótese, en efecto, las distintas especificaciones que pueden realizarse a partir de las palabras de quien fuera el director del Proyecto Genoma Humano:

Nos encontramos ahora en medio de una revolución genética que nos alcanzará a todos nosotros en numerosas maneras: esta revolución involucra enfermedades comunes como la diabetes, enfermedades cardíacas, cáncer, asma, artritis, Alzheimer, y más; salud mental y personalidad; decisiones acerca de la crianza infantil; e incluso nuestras historias étnicas. Ahora vemos que el lenguaje hablado por el ADN es el lenguaje mismo de la vida (Collins 2010, p.xiv; traducción propia). 
En términos generales, investigadores pertenecientes al programa de investigación de la Genética del Comportamiento creen en la familia de proposiciones cuyo ejemplar es $P_{m}$, destacando como factores internos elementos genéticos. Basta tan solo con exhibir las palabras con las que James Watson (2003, p.xxii), codescubridor de la estructura del $\mathrm{ADN}$, introduce uno de los principales libros de texto universitarios de genética del comportamiento:

Cuanto más viejos nos ponemos, más la mayoría de nosotros concluimos que los niños llegan al mundo con personalidades fijas que son difíciles de adscribir a las influencias del hogar o del ambiente escolar. Chicos particularmente felices parecen haber nacido de ese modo. Ahora, con el arribo de la secuenciación genómica del ADN humano y su lista de genes humanos, los procedimientos experimentales pronto estarán disponibles para finalmente resolver la larga contienda entre los argumentos del debate naturaleza-cultura (traducción propia).

Desde luego, uno fácilmente puede intuir hacia qué lado cree Watson que se inclinará la balanza. Pero, incluso, aun cuando se reconozca la importancia de factores ambientales, desde dicho programa de investigación se cree que hay "verdaderos efectos biológicos" en los genes a ser encontrados, efectos que predisponen a los individuos a desarrollar ciertos comportamientos (Turkheimer 2012). Robert Plomin y colaboradores (2016), por ejemplo, reconocen como uno de los hallazgos más robustos de la Genética del Comportamiento el hecho de que los genes en muchos casos median las asociaciones entre los factores ambientales y los comportamientos. En dicho trabajo, los autores afirman que:

[El hallazgo] sugiere una manera general de pensar cómo los genotipos se desarrollan en fenotipos, de un modelo pasivo impuesto por los ambientes a un modelo activo de experiencias seleccionadas en que los humanos seleccionan, modifican y crean experiencias en parte basados en sus propensiones genéticas. (Plomin et al. p.12; traducción propia)

Es decir, lo que en principio podría ser considerado una causa ambiental, puede ser reinterpretado como una variable que se encuentra causada genéticamente. En ese sentido, no hay dudas de que los genetistas del comportamiento consideran que ciertas especificaciones de la proposición $P_{m}$ son verdaderas.

Conviene ahora apreciar las actitudes doxásticas que otros investigadores generan hacia las especificaciones de la proposición modelo $P_{m}$. Investigadores identificados con la TSD niegan rotundamente la verdad de afirmaciones como las representadas por la familia de modelos reconocida anteriormente. Esta aproximación se centra en una unidad de análisis holística entre el organismo y su ambiente (Lerner 2016). En ese sentido, un sistema de desarrollo no coincide con el organismo individual ni con lo que podrían ser consideradas sus características intrínsecas - es decir, 
su carga genética, sus configuraciones neuronales, entre otras - . Por el contrario, un sistema ontogenético es siempre un organismo en su ambiente (Griffiths y Tabery 2013; Lerner 2016). Por lo tanto, "la tradicional dicotomía de las causas del desarrollo entre heredadas, innatas o genéticas en lo denominado 'naturaleza', por un lado, y adquiridas, experimentadas o aprendidas en lo denominado 'cultura', por el otro" (Stotz y Allen 2012, p.92; traducción propia) carece de sentido para dicha perspectiva. Contrariamente, la TSD procura indagar las interacciones entre diversos factores que afectan al desarrollo sin continuar estimulando esa falaz dicotomía. No existen niveles privilegiados de causación ni de explicación. Los genes, los mecanismos epigenéticos, las estructuras neuronales y los factores ambientales interactúan a través del tiempo en modos complejos y bidireccionales para dar origen a un determinado fenotipo comportamental (Griffiths y Tabery 2013). De hecho, la TSD niega que la flecha de determinación o explicación fluya exclusivamente de las entidades y procesos de niveles inferiores hacia los niveles superiores (Silberstein y Chemero 2013). Cualquier comportamiento es necesariamente contextual y dependiente de muchos factores del sistema del desarrollo. En efecto, "lo que una persona hace emerge, o está siempre surgiendo, a través de las dinámicas regulares de los procesos constitutivos" (Raeff 2016, pp.12-3; traducción propia). Consecuentemente, los comportamientos son considerados propiedades relacionales antes que disposiciones intrínsecas o individuales. En este contexto epistémico, por lo tanto, proposiciones del tipo $P_{m}$ son fuertemente rechazadas.

Llegados a esta instancia de la argumentación, resulta necesario pasar en limpio algunas consideraciones realizadas. El debate naturaleza-cultura puede ser entendido de diversas maneras. En algunos casos, los desacuerdos surgen porque los investigadores piensan en distintas preguntas y caracterizan los términos de la disyunción de modo diferente. Si bien esto puede ser entendido como un desacuerdo, el mismo puede ser resuelto percibiendo que cada una de las partes está entendiendo el debate de manera diferente. Otra veces, la disputa se basa en un confusión acerca de los niveles de organización involucrados y del fenómeno explicado. Esto acontece, por ejemplo, cuando una de los disputantes puede estar refiriéndose al desarrollo de un rasgo en un individuo mientras que el segundo de los disputantes puede estar haciéndolo a las diferencias en un rasgo determinado en un grupo de individuos. Sin embargo, una vez que dichos motivos de confusión son cancelados, asumiendo que los sujetos que desacuerdan lo hacen acerca de (aproximadamente) lo mismo, se observa que persisten actitudes doxásticas diferentes acerca de cierto conjunto de proposiciones que comparten un parecido de familia con la proposición $P_{m}$. Cabe, entonces, retornar a las preguntas originales. ¿Es razonable el desacuerdo? ¿Será que se sostiene porque alguna de las partes evalúa la evidencia de manera inadecuada? ¿Cómo deberían ajustar las actitudes doxásticas ante la percepción del desacuerdo si los sujetos en cuestión son pares epistémicos? En la próxima sección mostraré que el 
desacuerdo puede ser entendido como un desacuerdo fuerte y argumentaré que los sujetos epistémicos involucrados en el debate presentan buenas razones para mantenerse obstinados.

\section{El debate naturaleza-cultura como desacuerdo fuerte}

El primer desafío que enfrentamos es el de argumentar que, en efecto, el desacuerdo ocurre entre pares epistémicos. Para ello, debemos encontrar una respuesta a la pregunta: ¿se encuentra algunos de los sujetos involucrados en el desacuerdo en una mejor posición para juzgar las especificaciones de $P_{m}$ ? La respuesta, a mi criterio, es negativa. Cuando los sujetos epistémicos son científicos que responden a programas de investigación consolidados y cuando estos científicos utilizan los mismos medios de certificación académica, como ser la legitimación por pares a través de las revistas científicas, no hay motivos para creer en la superioridad de uno por sobre el otro. La descripción del debate realizada en el párrafo anterior incluyó trabajos de investigadores que han pasado por los mismos mecanismos de validación y que responden a los marcos teóricos consensuados de distintos programas de investigación. No hay buenos motivos, pues, para dudar de la condición de paridad cognitiva. ¿Qué decir de la condición de paridad evidencial? Aquí también considero que existen motivos suficientes para sostener que se cumple dicha condición. En general, los disputantes exhiben en sus reflexiones la familiaridad aproximada de todos los datos y argumentos relevantes para la controversia. Cuando, por ejemplo, a fines de 1970 y principios de 1980 el debate naturaleza-cultura alcanzó un pico de tensión a partir de la emergencia de la Sociobiología, los sujetos en desacuerdo mostraron estar bien familiarizados con la evidencia y los argumentos disponibles (Segerstrale 1986). Eso no impidió que distintos investigadores mantuvieran creencias incompatibles. En la actualidad, diversos trabajos sistematizan la evidencia y los argumentos de los disputantes (ver, por ejemplo, Fox Keller 2010; Tabery 2009), otorgando razones suficientes para considerar que la condición de paridad evidencial también se satisface.

Con todo, el recorrido hasta aquí trazado permite visibilizar un desacuerdo vivo en ciencias de la vida entre los que pueden ser considerados pares epistémicos. Los biólogos del comportamiento humano desacuerdan respecto a una familia de proposiciones que presenta a $P_{m}$ como proposición modelo y no existen buenos motivos para pensar que los colegas en desacuerdo presentan alguna desventaja cognitiva al momento de evaluar la evidencia disponible. A su vez, la mayoría está familiarizada con el desacuerdo y con los argumentos relevantes. Cabe retomar ahora las posturas propuestas por ciertos epistemólogos sociales que reflexionan en torno a los desacuerdos entre pares epistémicos. Recordemos que, ante la percepción de un 
desacuerdo con un par epistémico, algunos autores proponen conciliar y otros sostienen que, al menos en algunos casos, es permisible ser obstinado y mantener la actitud doxástica inicial. En el caso del debate naturaleza-cultura sucede que de hecho predominan posturas obstinadas (de lo contrario, el debate se habría resuelta hace ya mucho tiempo). ¿Implica esto que el desacuerdo se sostiene de forma irracional como podrían argumentar los conciliacionistas? Mi respuesta frente a esa pregunta es negativa. El motivo: se deben tener en cuenta las diferentes perspectivas epistémicas en juego.

$\mathrm{Al}$ abrazar la idea de que la relación de apoyo evidencial es triádica y que un cuerpo de evidencia $E$ apoya una proposición $P$ tan solo en relación con a una perspectiva epistémica $R$, debemos especificar a qué tipo de desacuerdo entre pares epistémicos responde el caso aquí analizado. Siguiendo la conceptualización de Lo Guercio $(2012 ; 2015 ; 2016)$, la paridad epistémica podía ser débil o fuerte, lo cual a su vez significaba que los desacuerdos podían ser fuertes o débiles, respectivamente. El debate naturaleza-cultura involucra, como ya fue reconocido, sujetos de diversas formaciones disciplinares. Por lo tanto, es de esperar que estas especialidades difieran en sus supuestos acerca de la naturaleza de la evidencia, en las reglas de apoyo de $E$ hacia $P$ y, fundamentalmente, en las metas epistémicas perseguidas. En particular, aquí hemos hecho hincapié en dos programas de investigación diferentes: el de la Genética del Comportamiento y el de la TSD. En lo que resta del apartado explicitaré algunos de los elementos de las perspectivas epistémicas involucradas. Una vez reconocido que las perspectivas epistémicas difieren y que la controversia puede ser entendida como un caso de desacuerdo fuerte, argumentaré que la persistencia del desacuerdo en el debate naturaleza-cultura no precisa ser explicada a través de factores irracionales.

\subsection{Sobre la naturaleza de la evidencia}

En el caso de la Genética del Comportamiento, la evidencia a favor o en contra de especificaciones de $P_{m}$ surge principalmente a partir de correlaciones entre variantes fenotípicas y variantes genotípicas en una población de individuos. Comenzando con metodologías poblacionales cuantitativas que permiten diseccionar la varianza fenotípica en una varianza genética y en una varianza ambiental, los estudios se orientan luego a identificar cuáles son los genes involucrados con la esperanza de lograr especificar las rutas moleculares que subyacen a un determinado comportamiento (Pallitto y Folguera 2017; Plomin et al. 2013). Para clarificar el punto, supongamos que cierto estudio indica que un $60 \%$ de la variación en un comportamiento $X$ se debe a variaciones genéticas entre un grupo de individuos. Lo que se procura hallar una vez obtenido ese dato son las variantes genéticas particulares que explican esa variación, es decir, qué regiones del genoma son las que al variar, generan variaciones 
en el fenotipo. Pero, en todo caso, tanto en la determinación de la varianza genética así como en la identificación de las regiones genómicas involucradas, los datos recabados responden a correlaciones. Sin la inclusión de otro tipo de metodologías y procedimientos, la genética del comportamiento no consigue dilucidar estructuras causales (Turkheimer 2012). No obstante, los genetistas del comportamiento toman dichas correlaciones como si efectivamente se tratasen de relaciones causales (ver, por ejemplo, Plomin y Asbury 2005). En ese sentido, lo que constituye una evidencia para la genética del comportamiento son datos correlacionales. Así el valor de verdad de especificaciones de $P_{m}$ se obtiene a partir de un cuerpo de evidencia de tipo correlacional. $\mathrm{O}$, dicho en otras palabras, la genética del comportamiento acepta las correlaciones como evidencia apropiada de ese tipo de proposiciones.

¿Qué decir de la naturaleza de la evidencia en el caso de la TSD? Para este programa de investigación, las correlaciones a las que apunta la Genética del Comportamiento no constituye evidencia de proposiciones del tipo $P_{m}$. Por el contrario, para que algo constituya evidencia, la aproximación exige datos que respondan a cómo interactúan causalmente diferentes factores en el desarrollo de un comportamiento. Ni la sola mención a un factor aislado, como pueden ser los genes en el marco de la Genética del Comportamiento, ni la sola apreciación de correlaciones es entendida y aceptada como evidencia de algo parecido a $P_{m}$. En palabras de Richard Lerner (2016, p.243):

En cambio, sin embargo, en la aproximación que abraza la complejidad (y que no la reduce a una entidad esencial), el proceso del desarrollo en sí mismo es el origen de la estructura y función del organismo; no hay información prexistente que puede ser separada del proceso del desarrollo ni tampoco un nivel de organización esencial al cual puedan reducirse los niveles superiores complejos (traducción propia).

A partir de lo dicho, es evidente que la naturaleza de la evidencia varía en uno y otro caso. Lo que constituye una evidencia hacia $P_{m}$ para la Genética del comportamiento no constituye evidencia para la TSD. Por más que tengan acceso al mismo cuerpo de información, construyen la evidencia de forma diferente. Veamos qué acontece con el próximo punto.

\subsection{Sobre los criterios de evaluación de $\mathrm{E}$}

En rigor de verdad, preguntarse por los criterios de evaluación de la evidencia cuando en los párrafos precedentes se ha argumentado que los pares epistémicos que desacuerdan difieren en lo que consideran que es evidencia de $P_{m}$ no parece tener mucho sentido ni relevancia en la argumentación. De todos modos, cabe realizar algunas sugerencias en aquellos casos en los cuales se aceptan los cuerpos de información cruzados como evidencias adecuadas. Las correlaciones establecidas por 
los genetistas del comportamiento entre variantes fenotípicas y variantes genotípicas son dependientes de la población que se tome para el estudio y del conjunto de ambientes que dicha población frecuente. Esto significa que las correlaciones no necesariamente replican bien de una población a otra. De hecho, esto es lo más frecuente (Turkheimer 2012). Ni la varianza genética se mantiene estable ni las regiones del genoma reconocidas se repiten. No obstante, los resultados suelen ser presentados como evidencia de influencias genéticas generales, para todo ambiente y población. Asimismo, aun cuando en casos en los que la varianza genética explique un $50 \%$ de la variación fenotípica, los genetistas del comportamiento, por el simple hecho de estar interesados en el nivel genético, otorgan un peso epistémico mucho mayor a los genes que a los factores ambientales. Así, incluso ante una aparente paridad causal (correlacional) entre los genes y el ambiente, la estructura teórico-conceptual del programa de investigación recoge solo lo referente a los primeros.

En cambio, para aquellos que trabajan bajo los esquemas de la TSD, cualquier cuerpo de información que solo rescate el nivel genético, aun cuando pueda ser reconocido como evidencia, posee un peso epistémico definitivamente menor. Este programa de investigación no privilegia ni ontológica ni epistemológicamente a ninguna entidad ni nivel de organización determinado. Por lo tanto, al momento de evaluar el valor de verdad de proposiciones del tipo $P_{m}$ los genes no tienen mayor peso que otros potenciales factores del desarrollo (Oyama 1985; Oyama et al. 2001; Stotz 2010). Definitivamente, los criterios de importancia de cierto cuerpo de evidencia difieren entre los genetistas del comportamiento y los pertenecientes al campo de la TSD. Los primeros están dispuestos rápidamente a aceptar información que pueda constituir evidencia genética mientras que los segundos precisan colocar esa información en el contexto de otros resultados.

\subsection{Sobre las metas epistémicas}

Por último, resta analizar a los disputantes en lo que refiere a las metas epistémicas de sus respectivos programas de investigación. Desde mi perspectiva, este punto es sumamente significativo para entender los desacuerdos en el debate naturalezacultura. La pregunta que cabe realizar es: ¿presentan las partes en desacuerdo las mismas metas epistémicas? De ser así ¿el orden de prioridades entre ellas coincide? En el caso de la Genética del Comportamiento, las siguientes palabras son indicativas:

Uno de los objetivos del Proyecto Genoma Humano fue la identificación de todos los genes. Poseer esencialmente la secuencia complete del genoma humano es similar a poseer todas las páginas del manual necesario para hacer el cuerpo humano. Ahora el desafío para los científicos es descubrir las bases genéticas de la salud y la enfermedad humana a través de la lectura y entendimiento de los contenidos de estas páginas [... U Un progreso rápido en 
estas áreas desafiantes mantiene la promesa de identificar incluso genes para comportamientos complejos influenciados por múltiples genes y factores ambientales (Plomin et al. 2013, p.18; énfasis y traducción propia).

O, como también es mencionado en otra sección:

Como fue dicho anteriormente, una de las metas más importantes de la investigación genética es la de proveer clasificaciones basadas en etiologías antes que síntomas (Plomin et al. 2013, p.245; énfasis y traducción propia).

A partir de lo dicho por estos genetistas del comportamiento, se infiere que una de las metas epistémicas privilegiadas por el programa de investigación es la predictibilidad y el poder de intervenir al ser humano. Desde luego, se pretende generar representaciones verdaderas. Sin embargo, la meta de predecir fenotipos a partir de ciertas configuraciones genéticas y la meta de generar herramientas de intervención a partir de ello resultan por momentos más importantes, siendo que se prioriza esa capacidad de manipulación por sobre el entusiasmo por la verdad (Pallitto 2017). Naturalmente, resulta ilustrativo y no entraña sorpresa alguna mencionar que la genética del comportamiento tiene sus orígenes en la ciencia práctica de la cría de animales (Turkheimer 2012).

Las metas epistémicas del programa de investigación de la TSD difieren en naturaleza y en su orden. La mayor preocupación de este programa reside en la posibilidad de generar representaciones verdaderas de la relación entre todos los factores y procesos que intervienen en el desarrollo de los comportamientos. En palabras de Helen Longino (2013, p.85):

La TSD se preocupa por caracterizar el complemento completo de factores interactuantes, el carácter de sus interacciones y la secuencias estadios de maduración. Los teóricos de los sistemas de desarrollo ven el punto de su trabajo como produciendo un entendimiento comprensivo de los mecanismos del desarrollo.

Como se reconoce que hay interacciones múltiples y complejas entre todos los factores intervinientes, difícilmente pueda predicarse que la predictibilidad constituye una meta de primera importancia. En tanto cada individuo es un sistema ontogenético diferente, difícilmente pueda predecirse un resultado a partir de la sola caracterización de algunos de los factores. Como consecuencia, el poder de intervención tampoco está entre los objetivos fundamentales. La meta que prima en dicho programa es el poder explicativo de las representaciones generadas, acusando a los genetistas del comportamiento de ofrecer explicaciones equívocas y simplificadas del comportamiento humano (Griffiths y Tabery 2013). 
De acuerdo con lo dicho en esta sección, una parte del debate naturaleza-cultura puede ser entendida como si se tratase de un tipo desacuerdo fuerte entre pares epistémicos débiles. Para convencerse de ello fue necesario mostrar, por un lado, que hay buenos motivos para considerar que los sujetos epistémicos que desacuerdan son pares epistémicos. Por otro lado, se hizo imperioso exhibir que los genetistas del comportamiento y los exponentes de la TSD difieren en cuanto a las perspectivas epistémicas adoptadas, esto es, en cuanto a cómo conciben la evidencia, a los criterios de evaluación de lo que consideran evidencia y a las metas epistémicas perseguidas. Por todo lo dicho, considero que el desacuerdo entre los biólogos del comportamiento no tiene por qué ser entendido como resultado de un mal desempeño en la apreciación de la evidencia por alguno de los sujetos epistémicos involucrados. Tampoco estimo necesario reducir el debate a la influencia de factores no epistémicos. Por el contrario, el reconocimiento de la presencia de perspectivas epistémicas diferentes permite vislumbrar que los pares epistémicos que desacuerdan pueden estar generando todos ellos actitudes doxásticas racionales. De haber cierta exactitud en los argumentos ofrecidos, considerar el debate naturaleza-cultura desde la perspectiva de los desacuerdos fuertes permite comprender, aun cuando se hayan eliminado las otras posibles fuentes de confusión, la dificultad de resolver la controversia. Asimismo, apoya la idea de que, en ciertas ocasiones, es razonable reaccionar obstinadamente frente al desacuerdo con un par epistémico.

\section{Consideraciones finales}

La controversia analizada constituye un valioso recurso empírico para las reflexiones filosóficas sobre desacuerdos entre pares epistémicos. Comúnmente, los trabajos en el campo de la Epistemología Social presentan aspiraciones normativas, es decir, versan sobre qué debería hacer un sujeto epistémico particular frente a la percepción del desacuerdo con un par epistémico, al margen de lo que efectivamente haga. Si bien todo ensayo o crítica filosófica requiere de cierta actitud normativa, en el caso de las reflexiones sobre cuestiones fácticas se vuelve imprescindible cierta dosis de descripción empírica de prácticas epistémicas concretas. Cómo se comportan de hecho los sujetos en estos sistemas ciertamente permite enriquecer las reflexiones, al visibilizar ciertos elementos o procesos que no pueden ser capturados recurriendo únicamente a abstracciones ideales. En el caso del debate naturaleza-cultura tal como se expresa en la Biología del Comportamiento, los pares epistémicos mantienen posturas obstinadas y existen buenos motivos para creer que son racionales al hacerlo. Sin embargo, dicha racionalidad no puede ser capturada por las posturas conciliadoras que no tienen en cuenta la práctica epistémica efectiva y los supuestos subyacentes de los sujetos que desacuerdan. Ni los proyectos puramente normativos 
ni los proyectos meramente descriptivos son suficientes. En algún lugar intermedio del espectro deben hallarse las respuestas adecuadas.

Por otro lado, la argumentación ofrecida permite concluir algunas cuestiones respecto a la controversia analizada. Como reconoce la cita con la que hemos iniciado el ensayo, lo que muchos autores que han reflexionado acerca del debate naturalezacultura continúan preguntándose es cómo una controversia que cualquier académico clama estar resuelta, sobrevive y se prolonga en el tiempo (Fox Keller 2010; Kitcher 2001; Lerhman 1970: Oyama 1985; Tabery 2009). Habiendo argumentado que parte del debate puede ser considerado como un caso de desacuerdo fuerte, espero haber arrojado algo de luz sobre la persistencia del debate. Pero, ¿qué es lo que la argumentación sugerida permite y no permite concluir? En primer lugar, la propuesta brindada no pretende dar cuenta de todas las variantes que adopta el debate naturaleza-cultura. Como hemos exhibido, la controversia engloba diferentes formas de desacuerdo. La diversidad de preguntas, explananda y explicaciones que caen bajo la temática imposibilita brindar una única respuesta adecuada. Por el contrario, cabe intuir que cada forma que adopta el debate presentará características particulares.

En segundo lugar, la argumentación tampoco procura establecer que la controversia debe ser explicada apelando únicamente a factores epistémicos y del tipo aquí considerado. La axiología del debate es sumamente compleja y nunca puede ni debe descartarse la presencia de valores no epistémicos. De hecho, hay quienes han explicitado sin tapujos las motivaciones políticas subyacentes a sus proyectos científicos (Lewontin et al. 1987). A su vez, existen otras propuestas que han intentado dar cuenta del debate en términos cognitivos como, por ejemplo, cuando se apelan a diferentes conceptualizaciones de las entidades genéticas (Griffiths y Tabery 2008) o cuando se clarifican ambigüedades del lenguaje utilizado (Fox Keller 2010). En ese sentido, aquí solo se propone otra de las tantas razones de tipo epistémicas para explicar la perseverancia del debate y las dificultades de ponerle fin.

Por último, cabe decir que, en tanto la Biología del Comportamiento continúe exhibiendo una pluralidad de perspectivas epistémicas diferentes, seguirán existiendo desacuerdos que perpetúen el debate naturaleza-cultura. Aunque "todos sepamos" que no es verdadero, todos a la vez lo continuamos alimentando. Motivos sobran, y entre ellos figuran, sin lugar a dudas y por mucho que les pese a los conciliacionistas, los de tipo epistémico o también llamados racionales. Mantenerse obstinado cuando el desacuerdo ocurre con par epistémico no implica, necesariamente, caer en la irracionalidad. La prolongada persistencia del debate naturaleza-cultura es una muestra de ello. 


\section{Referencias}

Christensen, D. 2007. Epistemology of disagreement: The good news. The Philosophical Review 116(2): 187-217.

Collins, F. 2010. The language of life. DNA and the Revolution in Personalized Medicine. Nueva York: Harper.

DiLalla, L. F. 2003. Behavior genetics of aggression in children: review and future directions. Developmental Review 22: 593-622.

Douven, I. 2009. Uniqueness Revisited. American Philosophical Quarterly 46(4): 347-61.

- 2010. Simulating peer disagreements. Studies in History and Philosophy of Science 41: $148-57$.

Elga, A. 2007. Reflection and disagreement. Noûs 41(3): 478-502.

Feldman, R. 2006. Epistemological puzzles about disagreement. In: S. Hetherington (ed.) Epistemology Futures, pp.216-36. Nueva York: Oxford University Press.

Fox Keller, E. 2010. The Mirage of a Space between Nature and Nurture. Londres: Duke University Press.

Frances, B. 2013. Disagreement. Cambridge: Polity Press.

Griffiths P. E. 2013. Developmental systems theory: What does it explain, and how does it explain it? Advances in Child Development and Behavior 44: 65-94.

Griffiths P. E.; Tabery J. G. 2008. Behavioral genetics and development: historical and conceptual causes of controversy. New Ideas in Psychology 26: 332-52.

Hulme, M. 2009. Why We Disagree about Climate Change. Cambridge: Cambridge University Press.

Jumonville, N. 2002. The Cultural Politics of the Sociobiology Debate. Journal of the History of Biology 35: 569-93.

Junges, A. L. 2013. Desacordo racional e controvérsia científica. Scientiae Studia 11(3): 61335.

Kelly, T. 2005. The epistemic significance of disagreement. Oxford studies in epistemology 1: 167-96.

- 2010. Peer Disagreement and Higher Order Evidence. In: R. Feldman; T. Warfield (eds.) Disagreement, pp.111-74. Oxford: Oxford University Press.

Kitcher, P. 2001. Battling the Undead: How (and How Not) to Resist Genetic Determinism. In: R. S. Singh; C. B. Krimbas; D. B. Paul; J. Beatty (eds.) Thinking about Evolution: Historical, Philosophical and Political Perspectives, pp.396-414. Cambridge: Cambridge University Press.

Lackey, J. 2010. A Justificationist View of Disagreement's Epistemic Significance. In: A. Haddock; A. Millar; D. Pritchard (eds.) Social Epistemology, pp.298-325. Oxford: Oxford University Press.

Lehrman, D. S. 1970. Semantic and Conceptual Issues in the Nature-Nurture Problem. In: L. Aronson; E. Tobach; D. S. Lehrman; J. S. Rosenblatt (eds.) Development and Evolution of Behavior, pp.17-52. Nueva York: W. H. Freeman.

Lerner, R. 2016. Complexity Embraced and Complexity Reduced: A Tale of Two Approaches to Human Development. Human Development 59: 242-9.

Lewontin, R. D.; Rose, S.; Kamin, L. J. 1987. No está en los genes. Barcelona: Crítica.

Lo Guercio, N. 2012. Philosophical peer disagreement. Logos \& Episteme 3(3): 459-67. 
2015. Desacuerdos entre Pares Epistémicos: Problemas y Soluciones. Tesis doctoral. Universidad de Buenos Aires.

— 2016. Desacuerdo entre Pares y Dependencia Epistémica. Principia 20(3): 325-41.

Longino, H. 2013. Studying Human Behaviour: How Scientists Investigate Aggression \& Sexuality. Chicago: The University of Chicago Press.

Machamer, P. K.; Pera, M.; Baltas, A. (eds.) 2000. Scientific controversies: philosophical and historical perspectives. Oxford: Oxford University Press.

Monares, R. A. 1999. Modernidad y crisis ambiental: en torno al fundamento de la relación naturaleza - ser humano en occidente. Revista Austral de Ciencias Sociales 3: 31-42.

Oyama, S. 1985. The ontogeny of information: Developmental systems and evolution. Cambridge: Cambridge University Press.

Oyama, S.; Griffiths, P. E.; Gray, R. D. 2001. Introduction: What is developmental systems theory? In: Cycles of contingency: Developmental systems and evolution, pp.1-11. Cambridge: The MIT Press.

Pallitto, N. 2017. Representar e intervenir el comportamiento humano en la era de la tecnobiología.Revista Colombiana de Filosofía de la Ciencia 17(35): 7-34.

Pallitto, N.; Folguera, G. 2017. Ni cabalmente clásico, ni completamente molecular. Un análisis del concepto de gen en la genética del comportamiento. Scientiae Studia 15(2): 43957.

Paul, D. B. 1998. The Politics Of Heredity Essays on Eugenics, Biomedicine, and the NatureNurture Debate. Nueva York: State University of New York Press.

Pigliucci, M. 2001. Phenotypic Plasticity: Beyond Nature and Nurture. Baltimore: The Johns Hopkins University Press.

Plomin, R.; Asbury, K. 2005. Nature and nurture: Genetic and environmental influences on behavior. Annals of the American Academy of Political and Social Science 600: 86-98.

Plomin, R.; DeFries, J.; Craig, I.; McGuffin, P. 2012. Behavioral Genetics in the Postgenomic Era. Washington D.C.: American Psychological Association.

Plomin, R.; DeFries, J.; Knopik, V.; Neiderheiser, J. 2013. Behavioral Genetics. Nueva York: Worth Publishers.

- 2016. Top 10 replicated findings from behavioral genetics. Perspectives on Psychological Science 11: 3-23.

Raeff, C. 2016. Exploring the dynamics of human development: An integrative approach. Nueva York: Oxford University Press.

Segerstrale, U. S. 1986. Colleagues in conflict: An "in vivo" analysis of the sociobiology controversy. Biology \& Philosophy 1: 53-87.

Silberstein, M.; Chemero, A. 2013. Constraints on localization and decomposition as explanatory strategies in the biological sciences. Philosophy of Science 80(5): 958-70.

Stotz, K. 2010. Human nature and cognitive-developmental niche construction. Phenomenology and the Cognitive Sciences 9: 483-501.

Stotz, K.; Allen, C. 2012. From Cell-Surface Receptors to Higher Learning: A Whole World of Experience. In: K.S. Plaisance; T. A. C. Reydon (eds.) Philosophy of Behavioral Biology. Boston Studies in Philosophy of Science, pp.85-123. Dordrecht: Springer.

Tabery, J. 2009. Beyond Versus: The Struggle to Understand the Interaction of Nature and Nurture. Cambridge: The MIT Press. 
Turkheimer, E. 2012. Genome Wide Association Studies of Behavior are Social Science. In: K. S. Plaisance; T. A. C. Reydon (eds.) Philosophy of Behavioral Biology. Boston Studies in Philosophy of Science, pp.43-64. Dordrecht: Springer.

Wedgwood, R. 2010. The moral evil demons. In: R. Feldman; T. Warfield (eds.) Disagreement, pp.216-46. Oxford: Oxford University Press.

White, R. 2005. Epistemic Permissiveness. Philosophical Perspectives 19: 445-59.

\section{Notas}

${ }^{1}$ Desde luego, hay quienes rechazan que tal distinción entre hechos y valores pueda ser realizada en primer lugar (Gómez 2014; Putnam 2002). No se pretende aquí tomar partido en dicha controversia, sino simplemente recoger una distinción propia de los trabajos que versan sobre desacuerdos racionales.

${ }^{2}$ Nuevamente, cabe aclarar que la construcción de proposiciones fácticas supone todo tipo de valores (Gómez 2014).

${ }^{3} \mathrm{En}$ ambos casos se da por sentado que tanto $S_{1}$ como $S_{2}$ son sujetos falibles.

${ }^{4}$ Se reconocen incluso otras posibles lecturas del dualismo naturaleza-cultura, tales como las correspondientes a los ambientalismos críticos que consideran que durante la modernidad el ser humano se ha separado de la naturaleza, estableciendo con ésta una relación de dominio y explotación (Monares 1999). Aquí el foco está puesto en el dualismo referido al comportamiento humano.

${ }^{5}$ La plasticidad fenotípica es la propiedad de un determinado genotipo de producir diferentes fenotipos en respuesta a diferentes condiciones ambientales (Pigliucci 2001). 